\title{
Industrial Design Education Based on Multi-Disciplinary Research
}

\author{
Yulin Zhao*, Delai Men \\ School of Design, South China University of Technology, Guangzhou, China
}

\section{Email address:}

512080653@qq.com (Yulin Zhao), Mendelai@163.com (Delai Men)

*Corresponding author

\section{To cite this article:}

Yulin Zhao, Delai Men. Industrial Design Education Based on Multi-Disciplinary Research. Science Innovation. Vol. 4, No. 2, 2016, pp. 50-55. doi: 10.11648/j.si.20160402.15

Received: February 25, 2016; Accepted: March 22, 2016; Published: April 11, 2016

\begin{abstract}
Industrial design was a highly integrated interdiscipline, which combined the scientific rationality and artistic emotion. Meanwhile, it was under the limitation and influence of many factors, such as environment, social morphology, cultural concepts, economy. Also, it was a creative design activity with the integration of function, form, technology and art. Industrial design was an interdiscipline which combined the artistic innovation and engineering discipline. This paper aimed at the current situation of industrial design education, then based on the analysis of its characteristics and discussed both the necessity of multidisciplinary cross and the interdisciplinary cross integration method of industrial design education in order to cultivate the applied talents who could adapt to the era development for complex industrial design. Thus, it could better promote and adapt to the development of economy, technology and other comprehensive national power in China.
\end{abstract}

Keywords: Industrial Design, Multidisciplinary Cross, Design Education

\section{基于多学科交叉的工业设计教育研究}

\section{赵雨淋 ${ }^{*}$ 门德来}

设计学院, 华南理工大学, 广州市, 中国

\section{邮箱}

512080653@qq. com（赵雨淋）, mendelai@163.com（门德来）

\begin{abstract}
摘要: 工业设计是一项高度综合性的交叉学科, 它融合了科学的理智与艺术的情感, 同时受环境、社会形态、文化观念 以及经济等多方面的制约和影响, 它是功能与形式, 技术与艺术为一体的创造性的设计活动。工业设计是一门艺术创新 与工程学科相结合的交叉学科。本文针对高校工业设计教育目前的现状, 在分析其学科特征的基础上, 分别探讨了多 学科交叉的必要性以及工业设计教育的多学科交叉融合合作方式, 培养适应时代发展的复合型工业设计应用型人才, 从而更好地适应且推进中国经济、科技等综合国力的发展。
\end{abstract}

关键词: 工业设计, 多学科交叉, 设计教育

\section{1. 引言}

青蛙设计公司的创始人艾斯林格 (Hartmut Esslinger) 曾指出:20世纪50年代是生产的年代, 60 年代
是研发的年代, 70 年代是市场营销的年代, 80 年代是金融 的年代, 而90年代则是综合的年代。科学技术发展日新月 异, 带来的不仅是严重的两极分化, 同时更多的是相互融 合。许多有关科学技术、经济文化和社会的重要问题都是 
交叉的, 其中诸如人口、资源、环境、生活科学等问题的 研究和解决方法都需要社会学和自然科学的合作, 需要多 种学科的理论、想法、观念、技术和方法的支持。事实上, 多学科、边缘学科和跨专业的研究已经成为世界科技突飞 猛进的关键, 培养具备多方面研究才能的人才成为现代工 业设计教育面临的重要任务。

目前, 中国的工业设计教育规模堪称世界第一, 但工 业设计教育的体系还不完备。工业设计专业是一门高度综 合性的交叉学科, 涉及到众多学科领域。在当今信息时代, 工业设计的这种综合性显得更加明显, 越来越注重设计过 程的连续性和完整性, 重视设计程序和方法论, 注重全面 提高设计师的综合素质。走向综合是工业设计的发展趋势, 也是工业设计教育必须遵循的发展方向。

\section{2. 中国工业设计教学的概述及现状}

\section{1. 中国工业设计教学的概述}

工业设计教学即工业设计学科的教师将知识、技能传 授给学生以及学生进行学习的过程。纵观世界, 工业设计 教学起源于 “Bauhaus”, 即包豪斯设计学院。在英国的“艺 术与工艺运动” 和以法国为中心的 “新艺术运动” 的推动 下, 1919年, 世界上第一所完全为发展设计教育而建立的 学校——“公立包豪斯学校” 在德国魏玛建立, 后改称 “包 豪斯设计学院”。中国的工业设计教育起步晚, 于 20 世纪 70 年代末开始萌芽。80年代初开始陆续有一些大学成立工 业设计系, 对工业设计教学进行最初的探索。“1986年, 工业设计被正式列入国家教育部所指定的专业教学目录, 成为一个正式的专业”。1987年, 工业设计协会成立。“伴 随着中国工业设计协会的成立, 我国的工业设计教育发展 推向了一个新的高潮”。90年代后, 中国的工业设计教育 开始进入成长期。

中国的工业设计经过这些年的发展, 理论体系不断完 善, 相关学术论文逐渐增多, 但还不足以支撑教育培养体 制。高质量、综合素质全面的工业设计师少, 很多学习工 业设计专业的学生都缺乏真正去 “设计” 的概念。工业设 计绝不仅仅是对产品的外观进行设计, 更深层次的是对人 的行为方式的改善, 促进人类向更好的方向发展。由于分 科而学, 艺术类的工业设计学生对造型的艺术了解较深, 而工科类的工业设计学生更专注于物体内部结构的学习。 因此工业设计的教学需要引进“多学科交叉性”这一概念。

\section{2. 现状}

截止2005年，中国经教育部备案或批准设置工业设计 本科专业的高等学校总数已达 230 个 (不包艺术设计专业 中设置的工业设计方向），名列设置最多的工科类专业的 前 8 名, 大大超过了绝大多数的传统专业。工业设计专业 的设置也日益呈现多样化趋势, 美术院校、工科院校、综 合大学、农林院校、师范院校都有设置, 在院校内部, 既 有单独设立的工业设计系, 也有设立在建筑学院、艺术学 院、设计学院、机械学院之下的工业设计系或专业。近年 来不少院校获得了设计艺术学的硕士及博士学位授予权, 设计教育的完整体系初步建立。专业求多求全, 专业划分
过窄, 专业界限太清、缺乏交叉综合等问题是中国的设计 教育目前普遍存在的问题。老师讲、学生听的灌输式、家 长式的教学方法, 缺乏启发式, 缺乏对话研讨, 忽视培养 学生的发现、分析和解决问题的能力和自学能力。忽略了 学生的创新和自主能力, 也就无法引导学生自愿自主的进 行创造性的设计, 严重制约了工业设计的发展, 使设计教 育的发展缓慢, 培养创造性人才的效果微弱, 对中国设计 教育产生着制约的影响。教育目标不明确也是影响中国设 计教育发展的另一个因素。目前, 中国国内设计专业的培 养目标可以说大多流于形式, 更无课程体系来保证, 因为 不少人认为这只是应付上级检查的文字工作, 对培养目标 的重要性认识不足。在美国、欧洲国家以及日本, 培养目 标作为办学宗旨、理念, 十分明确, 而且与课程体系相一 致, 这是确保教育质量的前提。此外, 课程体系和教学内 容有待建立, 结构体系不完善, 教学科学管理方式不强, 师资队伍和人才培养模式的缺陷, 都在一定程度上制约着 中国设计教育的发展。

世界各国正在不断调整教育发展战略, 改革教育思想、 学科专业结构、人才培养计划、教学内容和教学方法, 以 适应不断发展的社会。设计教育自然也不能例外。在社会 的飞速发展, 全球一体化的大趋势下, 学科间相互渗透、 相互依存已成为知识产出的一条基本定律。教育的发展方 向也要遵循这一规律。工业设计本身就属于边缘性、交叉 性的学科, 所以更需要通过 “融合” 的教育模式, 才能将 艺术与其它学科有机的联系在一起, 促进文、理、艺术等 学科的交叉、渗透机制, 进一步强化工业设计的学科边缘 性发展。工业设计教育的特点应该是多元化及交叉性的, 多学科整合发展的出现将成为现代设计教育新的培育方 式。学科交叉、学科融合、借鉴其他优势学科的有效教学 方法和手段, 培养复合型人才, 并以合作等方式进行学术 讨论和课题研究, 是工业设计教育在中国最主要的发展趋 势之一。

\section{3. 多学科交叉对于工业设计教育的必要性}

\section{1. 交叉学科的研究取向影响}

学科交叉研究是指科研主体在科学分化的基础上, 打 破不同学科之间的界限、跨越不同研究领域而进行一种科 学创造活动, 是解决复杂科学技术问题和社会问题而达到 不同学科相互渗透的一个重要手段。交叉学科研究近十年 来已经成为社会科学研究领域中的一个重要的研究方向, 而其研究取向同样影响到教育研究领域。一般认为交叉学 科研究是使教育研究取得重要成效的条件之一。

\section{2. 综合学科其特征的要求}

工业设计作为综合学科, 其综合特征要求对人才培养 的目标, 是与多学科交叉融合、多层面复合所具备的坚实 基本功。如果仅专业基础课和专业课, 往往很难解决其综 合性特征所要达到复合型人才培养目标的难题。因此必须 具备广博的跨学科知识和技法, 坚实的基本功, 才可能在 相关学科之间交叉融合渗透的过程中建立起完整的工业 设计知识架构。工业设计所要解决的问题, 绝不是仅运用 
本专业知识就可以的, 进行工业设计涉及到从生活上的小 细节萌发出的创意再到创意的具体化，进而对人与物、社 会、经济、技术的调查研究，找到合适的方向深入设计。 它不仅要融会贯通横向联系的视觉传达设计、室内设计、 环境设计等学科的知识, 还要运用到纵向关联的人文、理 工等其他学科的认识。工业设计是以人为主体, 为了使人 们进行更方便、简洁的操作, 需要运用到心理学、人机工 学等的知识, 这就涉及到了其他学科知识的学科与应用。 如日本设计师原研哉为中年妇女设计的以香皇为原型的 手机, 他充分考虑了用户的使用心理并与设计相结合, 消 除了中年妇女使用高科技产品的畏惧心理。“我国有些院 校在校内开设了特定形式的研究中心或团队组合, 通过科 研课题或实际项目促进学科院系间的交叉合作, 取得良好 的效果和成就。” 将 “交叉性学科” 这一概念引入到工业 设计的教学中, 可以促进工业设计教育的发展, 培养出高 质量、综合素质全面的工业设计专业人才, 设计出更贴合 人们实际的产品。

因此在了解目前工业设计教育现状的基础上, 分析其 学科特点及交叉学科的研究对于教育领域的重要影响, 多 学科交叉融合研究应用在工业设计教育上是必不可少的。

表1 中国某高校一学年专业课程课表。

\begin{tabular}{lll}
\hline \multirow{2}{*}{ 序号 } & 工业设计专业课程课时表 & \\
\cline { 2 - 3 } & 必修课名称 & 学时 \\
\hline 1 & 造型学 & 64 学时 \\
2 & 设计综合表达 & 48 学时 \\
3 & 工程图学 & 48 学时 \\
4 & 色彩学 & 48 学时 \\
5 & 模型制作H & 48 学时 \\
6 & 视觉传达设计 & 48 学时 \\
7 & 公共设施设计 & 48 学时 \\
8 & 工业设计概论 & 48 学时 \\
9 & CAID基础 & 32 学时 \\
10 & 设计形态基础 & 32 学时 \\
11 & 人机工程学 & 32 学时 \\
12 & 设计方法与程序 & 32 学时 \\
13 & 产品调查与观测 & 32 学时 \\
14 & 并行工程基础 & 32 学时 \\
15 & 产品系统设计 & 32 学时 \\
16 & 结构素描 & 32 学时 \\
17 & 设计形态学 & 32 学时 \\
\hline
\end{tabular}

\begin{tabular}{lll}
\hline \multirow{2}{*}{ 序号 } & 工业设计专业课程课时表 \\
\cline { 2 - 3 } & 必修课名称 & \\
\hline 18 & 技能结构与材料 & 学时 \\
19 & 交通工具设计 & 32 学时 \\
20 & 设计心理学 & 32 学时 \\
21 & 产品规划策略 & 32 学时 \\
22 & 设计比教学 & 32 学时 \\
23 & 信息互动设计 & 32 学时 \\
24 & 价值工程分析 & 32 学时 \\
\hline
\end{tabular}

\section{4. 工业设计教育中多学科交叉合作方式}

\section{1. 固定形式的多学科融合一一学分制的workshop}

将多专业多学科的交叉合作以Workshop的形式实现, 给予适当的学分, 使其成为一门选修课程被安排到整个课 程体系中。

学分制的优势: 1. 时间弹性大。学生可根据兴趣、爱 好进行, 充分发挥主观能动性, 优化知识结构和养成自我 培养意识。2. 淡化班级制度, 按需要组成集体。这样可以 培养学生的配合协作意识。在美国, 不同年龄、不同年级 的学生同修一门课的情况很普遍。这样, 可以把学生共同 融入到一个大范围内, 能增强学生的协作能力。3. 有利于 “因材施教”, 学生可按市场需求进行择课, 有利于实践 与理论的结合, 符合综合素质的培养。

设计教育中, 可以将多学科的交流合作与学分制配合, 以组建学分制Workshop的形式实现。其特点为：（1）以 设计专业师生为主体, 同时吸纳其他设计相关学科的师生 加入Workshop, 共同研究学习进行合作。（2）Workshop 形式由于具备适当的学分被安排到学校的选修课中, 因此 其他专业学生也可自主根据兴趣爱好选择加入学习, 一定 程度上提高学生学习的主动积极性, 促进学习效率的提高, 同时不同专业学生通过Workshop形式平台共同研究学习, 可以最大限度丰富其专业背景。（3）不同专业背景教师 通过其平台, 更加丰富了自身的理论知识与实践技能素养, 从而可以更好地投入教学科研工作。(4) 教师可以将学 习课时、完成项目数量、个人突出贡献等作为考核标准, 判定是否授予学生学分, 学分的授予标志其成员合格地完 成课程任务。同时学分判定标准的设定, 学生可灵活地加 入或离开Workshop, 有利于创新设计和多角度思维的拓展。

\section{学分制的WORKSHOP}

\section{优势性内容}

1.时间弹性大 2.淡化班级制度组成集体
3.有利于因材施教
特征性内容

\begin{tabular}{|l|l|l|}
\hline \multicolumn{2}{l|}{} & \multicolumn{1}{|c|}{} \\
\hline 1. 多学科背景 & 2. 以兴趣为导向 & 3. 灵活的学分授予体系 \\
\hline
\end{tabular}

图1 学分制的WORKSHOP。

\section{2. 固定目标的多专业多学科融合一一以研究项目为中 心的合作}

和学分制的Workshop不同, 以项目为中心的合作是以 完成项目为目的的, 所以项目组的成员在合作团队成立之
初就已经确定了, 并且在项目进行过程中人员变动甚微, 才队的稳定性得以保证。以项目为中心的合作，需要建立 一个以工业设计教学研究为核心、跨学科、目标明确、成 员个性鲜明、开放性的多学科合作团队, 由多学科或多领 域的成员组成, 使许多院系或中心都参与进来, 促使不同 
学科或领域进行学术交流与合作。核心在于合作, 它以完 成任务为目标, 打破学科间的壁垒, 有利于资源的共享、 信息的传递、人员的协调。合作团队改变了死板的组织结 构模式, 减少了不必要的工作流程和学科间屏蔽的影响, 有利于更有效率的完成产品研发的任务。

这种合作团队，根据不同的目标和条件，产生不同规 模的团队, 不同的团队规模在应用上会有不同的效果。不
同规模的团队可以应用多样性的形式, 如小型团队为互助 小组, 中型团队可以为固定的合作中心, 大型团队可以建 立一个学科广泛、设备齐全的合作机构。以研究的目的、 研究的经费、研究的时间为依据, 来确定成立何种规模和 形式的合作团队。

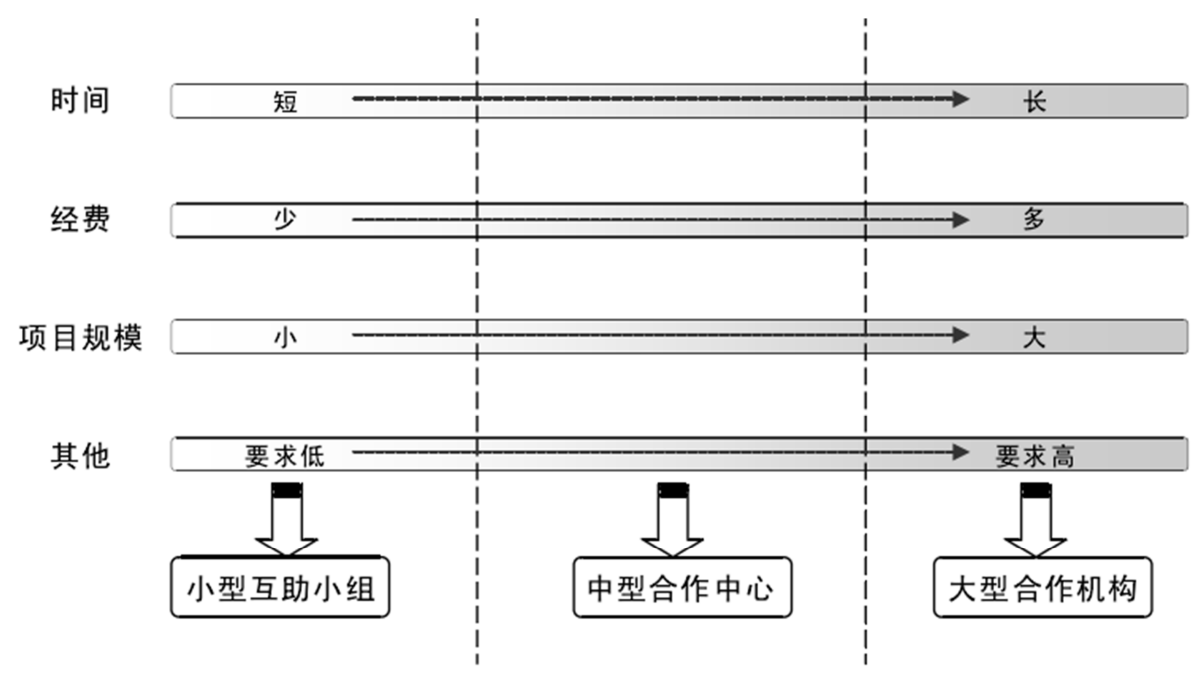

图2 以研究项目为中心的合作。

当研究的课题比较正式, 可以考虑成立合作团队。这 样的团队需要有固定的活动地点, 可以在设计艺术学院内 占用一间工作室, 拥有几台计算机设备, 并连接上网, 这 样固定的空间便于日常的交流, 学生与学生之间、学生与 教师之间可以随时沟通。同时团队内小组成员包括设计类 学生和一部分相关学科的学生。有固定的指导教师参与其 中, 带领成员完成各个项目。合作团队的优势在于小组成 员相互之间比较熟悉, 易于沟通; 成员熟知度较高, 易于 指导; 因为项目规模中等, 学生利用课外时间即可以完成 项目, 牵扯的精力不大, 不会影响学生在本专业的学习。 同时还能开拓视野, 增长社会实践能力。

\section{3. 设计专业内部的融合一一导师制或工作室制}

该形式源于西方美术教学的体制, 在中国艺术专业由 来已久。这种教学体制可以更好地贯彻全员育人、全过程 育人、全方位育人的现代教育理念, 更好地适应素质教育 的要求和人才培养目标的转变。该制度要求在教师和学生 之间建立一种 “导学” 关系, 针对学生的个性差异, 因材 施教, 指导学生的思想、学习和生活。学习的方式主要是 以课题为中心, 同时辅以相关的讲座。

在中国的设计教育中实施导师制和工作室制, 目前主 要是以研究生教学为主, 相同导师的研究生在同一个工作 室进行学习、研究、项目设计, 便于交流和资源共享。通 过丰富灵活的训练课题, 启发和引导学生创造性的理解艺 术与设计的关系, 注重学生整体素质培养和思维方式的训 练, 培养学生的创造性思维和全程设计于思考的能力。导 师制和工作室制在研究生教学中起到了积极的作用, 同时 在本科生教学中应该也逐渐引入导师制这种教学模式, 组
织骨干教师, 在高年级本科生中定点定人进行因材施教的 制度, 强调学科综合的特性。从而提高学生的综合能力, 弥补课堂教学环节中大学生基本能力和素质培养方面的 不足, 更好地完成大学本科教学任务。

导师制和工作室制的优点:

第一, 突破传统属性结构教育模式, 知识贯通以网状 结构展开。传统的教学模式基本上是教师向学生进行灌输 式的“树形教育结构”。而在导师制和工作室制的模式下, 本科生、研究生、博士生、讲师、教授、学科带头人在同 一个环境下一起研究同一课题, 知识的传递性突破了传统 模式下的教学单向运动, 知识互补, 资源共享, 创建了教 与学、学与学互动的 “交叉往复” 的教学新环境。实现了 双向互动式、参与式、启发式于一身的教育模式。

第二, 导师制和工作室制有利于促进学生知识向能力 的转化。通过在工作室进行课题和项目的研究, 经常可以 将所学的知识加以应用, 在实践中提高了自身的实际操作 能力。导师制和工作室制, 由于其自身的特点决定了它的 实践性, 同时又有导师和共同学习的成员的指导和帮助, 因此, 在学生的知识能力转化过程中可以起到重要的辅助 和催化作用。

第三, 教师的积极性得到调动与发挥。导师制和工作 室制对教师来说即使压力也是动力, 由于要更多的面对学 生, 而教师的一言一行对学生起着示范作用, 这大大提高 了教师的责任心和敬业精神, 有利于促进教师素质的提高。

第四, 个性化教育的落实及创新精神的培养。打破了 传统的 “单一性” 教学。由于学生个体的差异, 能力和优 势各有不同, 在导师制和工作室制的模式下, 由于导师面 对的是不同层次的学生, 因此, 导师可以因材施教, 针对 每个学生的特点安排任务, 合理安排各个年级学生的课题, 
循序渐进地引导学生并培养其自信心, 真正发挥每个学生 的优势。且学生之间在不断的交流中, 通过对比, 更能准 确找到自身的定位, 为今后的职业生涯打下基础。

\section{4. 更广泛地融合方式一一开放性合作模式}

多种学科交流合作的设计教育, 成员的背景完全可以 不限于本院校内的师生, 合作方式也不限于工作室、 Workshop和项目团队的形式。可以应用更加开放的形式。 如校际、国际的交流合作，网络沟通、校企合作、与政府 的合作等。

(1) 校际合作: 以高校为主体要求两个以上的大学, 在教学、科研和社会服务等活动上进行合作, 通过共同的 投入和努力达到一定的办学目的。每所院校的优势学科各 不相同, 将学科间的合作扩大到大学与大学合作的范围, 可以充分有效地整合学术资源, 进行优势互补。（2）校 企合作: 参与实际项目的过程, 可以为学生提供实践机会, 是项目本身成为学生了解社会的窗口, 可以将科学技术很 快地转化利用, 产生经济的效益, 成为中心的研究经费, 为更好的理论研究提供了有利的条件。换言之, 通过校企 合作, 是企业得到人才, 学生得到技能, 学校得到发展; 从而实现学校与企业 “优势互补、资源共享、互惠互利、 共同发展” 的双赢结果。（3）网络合作：现代通讯技术 的发展, 网上所提供的巨大信息资源, 拓宽了知识视野和 思维方式。通过网络的沟通交流, 可是多学科之间合作更 便捷, 同时可冲破时间空间地域的限制, 系统地整合更加 广泛的学习资源。

\section{5. 学科融合教学的范例研究一一以华南理工大 学设计学院“ $\mathrm{C}-\mathrm{Lab}$ 跨学科拔尖创新设计人才 培养试验区” Workshop为例}

\section{1. C-Lab跨学科拔尖创新设计人才培养试验区简介}

华南理工大学设计学院 C-Lab, 全名是Creative laboratory, 它于 2014 年9月诞生, 由一名教授和 9 名不同 学科背景的设计学研究生组成, 在视觉传达、工业设计、 交互设计和多媒体设计均有所涉猎, 专注设计研究、科技 前沿、艺术美学等领域。

成立的一年来, 顺利举办多次海外名师课程, 与台湾 云林科技大学、日本武藏野美术大学联合举办多次海峡两 岸交流工作营, 邀请到数位国际知名大学的教授到设计学 院讲学授课。同时, 实验室的同学由多项科研成果发表。

目前在华南理工大学设计学院内有固定的工作室, 并 且为每位成员配备了个人 $P C$ 机。当有项目进行的时候, 创 新团队的成员会在工作室中交流观点, 同时工作室内分割 出了教师的办公区域, 学生也可与教师进行无障碍的交流。 创新团队的固定指导教师为华南理工大学设计学院的门 德来教授。门教授充分支持团队的建设, 并同时对团队内 的多个项目进行指导。同时实际项目与概念课题穿插进行, 不但增加了学生的设计经验和实践能力, 还充分从吸取了 国际上各类技术、功能等前沿信息, 大大的开拓了学生的 眼界。

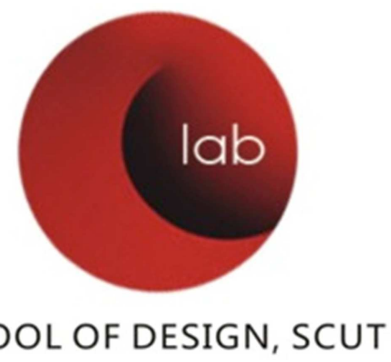

图3 C-Lab跨学科拔尖创新设计人才培养试验区的标志设计。

\section{2. 多学科融合理念在团队中的运用}

C-1ab创新团队从成立之出, 就本着融合多种学科特 点和优势, 进行工业产品设计的初衷, 广泛吸纳多种学科 背景的学生加入团队。虽然在团队刚刚成立的时候, 成员 只有 6 人, 分别是视觉传达设计、工业设计、数字多媒体 设计、包装设计。

\section{3. 实例的应用研究}

2014年9月6日至13日，“海峡两岸岭南文化特色调查 研究及设计实践”工作营在设计学院跨学科拔尖创新设计 人才培养试验区 (C-Lab) 成功举办。22位来自台湾云林 科技大学设计学院的导师、硕士和博士研究生与设计学院 师生进行了为期八天的交流活动。在工作营中共同对岭南 建筑及园林进行深入调查、研讨和挖掘, 从传统文化之美 的角度, 扑捉和发现文化创意元素。

(一)授课: 工作营以胡文波老师和石拓的授课开始, 胡老师从文化创意设计思维切入, 结合许多文化设计案例, 有趣生动地给同学们展示了别样的设计思路, 突出了设计 思维的重要性。石拓老师则以其岭南建筑史的学识背景为 基础, 为同学们解读广东岭南特色建筑, 并以 “清晖园” 和 “陈家祠” 为案例, 从整体历史背景到建筑特色介绍了 两个建筑的特点, 并着重分析其木雕、砖雕、铁铸、旗杆、 满洲窗、假山等元素。

（二）采风: 有了授课的背景, 同学们对两个建筑有 了初步的认识。根据此前在网络上收集了一些资料和设计 的初步设想, 分别对清晖园和陈家祠进行了针对性地考察 和调研。调查过程中, 分别邀请了导游讲解员为同学们进 行详细的讲解, 对建筑本身的历史和每一个园和厅的特色 做了具体的分析。同学在考察的过程一边拍摄记录, 一边 进行小组讨论。在采风的过程中对此前形成的初步的设想 进行调整和优化。在期间一个相对闲暇的下午, 工作营安 排了全体师生去黄埔军校参观和了解。

（三）设计：在日程安排中, 设计讨论作为重要的一 个环节, 占用一天的时间。根据小组讨论出的数个方案, 每个小组的同学和各组指导老师进行探讨和分析。结合岭 南建筑的特色和历史背景元素, 对各个小组的方案的优缺 点进行评估。每个小组的设计方案经过一次又一次的改造 优化、甚至重新发想创造, 最终每个小组确定一个方案。 在剩余的两天中, 同学们处于不停地改良-测试-改良-测 试的反复改错过程, 在连续数个通宵之后, 各自完成了针 对陈家祠或者清晖园建筑的平面设计作品。 
（四）发布: 每个小组以汇报和实物展示的形式向老 师同学们讲解各自的设计, 各位指导老师也对每个作品提 出自己的看法和仔细的分析评价。有针对陈家祠做广告设 计、邀请函设计、门票设计、包装设计、导览图设计、企 业形象设计, 也有做交互形体验设计、折纸望远镜等, 也 有针对清晖园做文化笔记书设计。每个小组设计别出心裁, 得到了老师们的肯定, 同时, 也获得了老师修改建议和客 观的评价。
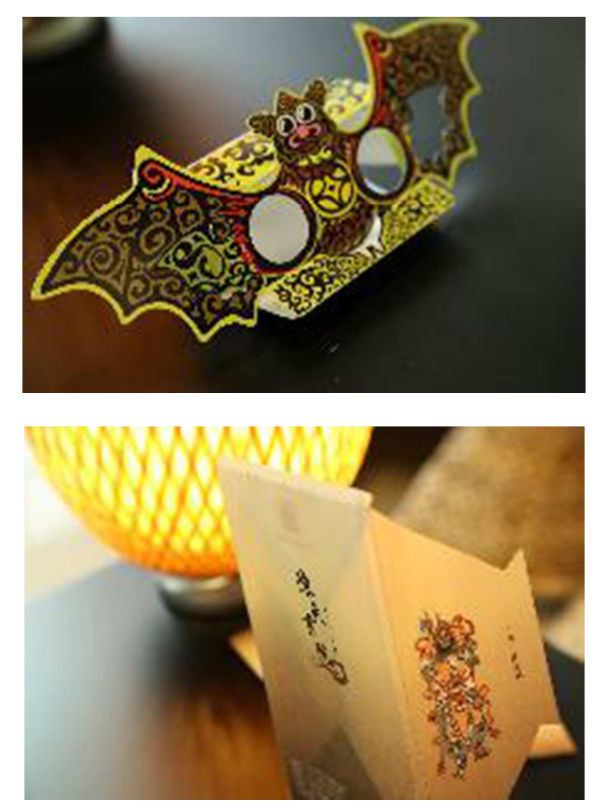

图4 C-Lab跨学科拔尖创新设计人才培养试验区工作营作品。

\section{6. 结束语}

随着社会的快速发展和不断进步，对于目前中国工业 设计教育而言, 重视多种学科交叉融合的人才培养方式, 这无疑是培养优秀设计人才的重要途径之一, 并且也是当 今设计发展寻求突破的一个新契机。加强学科交叉合作, 努力培养良好的工业设计复合应用型人才, 从而更好地适 应我国社会经济的快速发展步伐。

\section{致谢}

感谢我的导师门德来教授的认真指导, 同时, 也要感 谢我热爱工业设计的同学们, 他们勤恳的工作和富有创造 性的艰辛探索为我的论文提供了良好的研究素材。

\section{参考文献}

[1] 戴志锋. 校企合作、校校合作与学科交叉的融合性探索与实 践. 计算机教育, 第23期, 2011. 12

[2] 张贤富. 基于市场需求的工业设计教育 $[\mathrm{J}]$. 大众文 艺. 2013 (11)

[3] 肖瑞峰. 大学的课程思想与建设策略 $[J]$. 中国高教研究, 2009, （6）

[4] 信建英. 市场经济下中国工业设计教育 $[J]$. 剑南文学 (经典 教苑). 2013 (09)

[5] 段齐骏, 李亚军, 王展. 工业设计教育的 “有效” 策略 [J]. 中国大学教学. 2012 (01)

［6］曹小琴. 面向 “两化融合” 的工业设计专业课程体系构建研 究 [D]. 武汉理工大学 2013

[7] 鲍懿喜. 工业设计的视觉文化研究 [D]. 华东师范大学2013

[8] Jona E Schroeder. visual Consumption. 2005

[9] Wysocki, Robert K. Effective Project Management: Traditional, Adaptive, Extreme. [M]. 5st ed., Wiley publishing, Inc, Indiana. 2009

[10] Benny Ding Leong. The Revitalization of Traditional Chinese Culture for New Product Design. Hong Kong Polytechnic University. 2008 